\title{
KEPUASAN KONSUMEN TERHADAP ATRIBUT KUALITAS MINUMAN KOPI DI JAVA PREANGER COFFEE HOUSE BANDUNG
}

\author{
Rayi Rahmanissa, Agriani Hermita Sadeli \\ Program Studi Agribisnis Fakultas Pertanian Universitas Padjadjaran \\ J1. Raya Bandung Sumedang KM 21, Jatinangor 45363 \\ E-mail: agriani.hs@gmail.com
}

\begin{abstract}
ABSTRAK
Penelitian ini bertujuan untuk mendeskripsikan karakteristik konsumen minuman kopi, kesesuaian tingkat kinerja dengan kepentingan atribut kualitas dan tingkat kepuasan konsumen mengenai atribut kualitas produk minuman kopi di Java Preanger Coffee House, Bandung. Penelitian didesain secara kuantitatif dengan analisis Importance Performance Analysis dan Customer Satisfaction Index. Hasil penelitian terhadap 62 orang responden menunjukkan bahwa (1) konsumen didominasi laki-laki, berpendidikan sarjana, berusia 25-30 tahun, pekerjaan wiraswasta, tinggal di kota Bandung dan berpendapatan di atas Rp5.000.000 per bulan; (2) Berdasarkan hasil perhitungan IPA, atribut yang memiliki kepentingan tinggi dan kinerja yang memuaskan meliputi atribut rasa, kualitas, bahan baku, kenyamanan tempat serta pelayanan. Atribut yang memiliki tingkat kepentingan yang tinggi namun kinerjanya perlu ditingkatkan adalah atribut harga, aroma dan cara penyajian. Atribut yang memiliki kinerja yang biasa saja serta tingkat kepentingannya rendah adalah atribut manfaat, tampilan fisik, ukuran volume dan informasi menu. Sementara, atribut yang konsumen anggap kurang penting pengaruhnya namun kinerjanya berlebihan adalah atribut variasi rasa. (3) Hasil perhitungan indeks kepuasan konsumen menunjukan bahwa konsumen merasa puas atas kinerja atribut kualitas produk secara keseluruhan. Perusahaan harus meningkatkan kualitas produknya sehingga sesuai dengan harga yang ditawarkan, memberikan pelatihan kepada pramusaji, menggunakan teknik pengolahan kopi yang lebih baik. Sedangkan untuk penelitian selanjutnya sebaiknya diteliti kegiatan pemasaran promosi dan distribusi terhadap kepuasan konsumen
\end{abstract}

Kata kunci: kepuasan konsumen, atribut kualitas, Customer Satisfaction Index, Importance Performance Analysis, kopi.

\begin{abstract}
The aim of this research is to analyze consumers' characteristic, the level of conformity between importance and performance level of coffee's quality attributes and the overall satisfaction level of consumers towards quality attributes of coffee in Java Preanger Coffee House. Design of this research is quantitative with 62 respondents. This research used descriptive analysis, Importance Performance Analysis and Customer Satisfaction Index. Results showed 1) the major consumers in Java Preanger Coffee House are men which age around 25-30 year old that have job in private sector. They live in Bandung, have allowance per month more than Rp5.000.000 and have bachelor degree; (2) Based on Importance Performance Analysis, attributes that have high importance and performance are taste, raw material quality, convenience place, and service atrribute. Attributes that the performance should be increased are price, flavor, and serving method. Attributes that have average performance and low importance are benefit, physical appereance, coffee volume, and information menu. Attribute that has low importance but has too much performance is variance of flavor; 3) The Customer Satisfaction Index calculation showed that Java Preanger Coffee House consumers are overall satisfied with performance of the coffee drinks quality attribute. Companies should improve the quality of their products to match the price offered, providing training to waiters and using better coffee processing techniques. Further research should be investigated the impact of distribution and promotion marketing activities on customer satisfaction.
\end{abstract}

Keywords: customer satisfaction, quality attribute, Customer Satisfaction Index, Importance Performance Analysis, coffee. 


\section{PENDAHULUAN}

Komoditas kopi merupakan komoditas perkebunan yang memiliki banyak penggemar dari segala kalangan, termasuk di Indonesia. Hal ini ditunjukkan dengan adanya peningkatan konsumsi kopi di Indonesia yang cukup signifikan pada beberapa tahun terakhir. Asosiasi Eksportir Kopi Indonesia melakukan survey di mana hasilnya adalah kebutuhan kopi Indonesia naik sebesar 36 persen dari tahun 2010 hingga tahun 2014. Selain itu, Indonesia pun termasuk konsumen kopi terbesar kedua seAsia Tenggara dan Timur setelah Jepang dan terbesar kedelapan di dunia dengan total konsumsi sebanyak 3.600.000 karung pada tahun 2012.

Gambar 1 menunjukkan bahwa rata-rata setiap tahunnya konsumsi kopi masyarakat Indonesia meningkat. Peningkatan paling signifikan terjadi pada tahun 2007 di mana pada tahun tersebutlah trend kedai kopi sedang berkembang dengan pesat. Semakin menjamurnya kedai kopi ini juga ternyata berperan dalam peningkatan konsumsi di dalam negeri. Perkembangan kedai kopi di Indonesia juga diakibatkan oleh meningkatnya taraf hidup dan pergeseran gaya hidup masyarakat perkotaan di Indonesia yang mendorong terjadinya pergeseran dalam pola konsumsi kopi, di mana saat ini mengonsumi kopi sudah menjadi gaya hidup sebagian penduduk Indonesia. Melihat gaya hidup tersebut, kedai kopi hadir menawarkan konsep one stop shopping di mana pengunjung dapat memperoleh keinginannya dalam satu tempat (Rachmad, 2014).

Java Preanger Coffee House adalah salah satu kedai kopi di kota Bandung yang baru berdiri pada tahun 2013. Sama halnya dengan bisnis-bisnis lain, Java Preanger Coffee House yang baru berdiri sekitar satu tahun lamanya ini tentunya memiliki pesaing-pesaing lain khususnya di kota Bandung yang menjadikan tantangan bagi usahanya. Melihat banyaknya usaha kedai kopi yang terdapat di Bandung, Java Preanger Coffee House dituntut untuk selalu mempertahankan bahkan meningkatkan performance perusahannya untuk memenangkan persaingan.

Menurut Fornell dkk (1996), untuk meningkatkan dan mengevaluasi performance perusahaan dapat dilakukan dengan mengukur kepuasan konsumen melalui kualitas produk dan jasa yang dialami oleh konsumen yang mengkonsumesi produk dan jasa tersebut.
Kualitas produk merupakan faktor yang sangat penting dalam mempengaruhi kepuasan konsumen (Rahayu dalam Anggita, 2014).

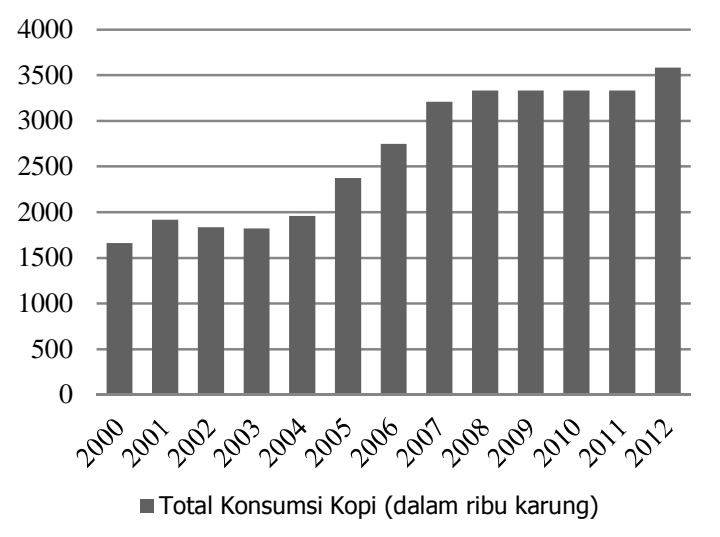

Gambar 1. Total Konsumsi Kopi di Indonesia Tahun 2000-2012 (dalam ribu karung)

Sumber: International Coffee Organization (2014)

Atribut kualitas produk minuman kopi merupakan salah satu aspek yang sangat penting dalam mengukur kepuasan pelanggan di sebuah kedai kopi, termasuk di Java Preanger Coffee House. Kualitas produk seringkali disikapi secara berbeda oleh konsumen karena perbedaan faktor kepentingan masing-masing konsumen (Weni dkk, 2011). Dalam mengevaluasi suatu kualitas produk minuman kopi, konsumen tentunya memiliki kriteria atau standar mengenai kualitas produk seperti apa yang baik dan diinginkannya. Pengevaluasian tersebutlah yang menjadi penentu penting dalam penilaian kinerja suatu produk sehingga produk minuman kopi dari Java Preanger Coffee House diharapkan dapat memuaskan konsumen melalui atribut-atribut kualitasnya.

Sudah banyak literatur yang membahas permasalahan kekuatan dalam kerjasama relasional business-to-business dalam pelaku pemasaran tetapi secara umum mengabaikan konsumen (Matanda, 1999). Oleh karena itu perlu untuk dilakukan penelitian yang bertujuan untuk menganalisis kepuasan konsumen. Kepuasan konsumen ini dilihat dari atribut kualitas produk minuman kopi, sehingga pihak Java Preanger Coffee House dapat memfokuskan atribut mana yang harus diprioritaskan untuk meningkatkan kepuasan konsumen, di mana kepuasan inilah yang menjadi alat bagi konsumen untuk membandingkan hasil yang dirasakan dengan harapannya. Selanjutnya, konsumen yang merasa puas akan suatu produk memiliki 
potensi yang besar untuk melakukan pembelian ulang yang menjadikannya konsumen dengan loyalitas tinggi.

\section{METODE PENELITIAN}

Penelitian ini dilaksanakan di Java Preanger Coffee House yang terletak di Jalan Cisangkuy no. 68, Bandung, Jawa Barat. Desain Penelitian ini menggunakan desain penelitian kuantitatif dengan jenis penelitian survey dan teknik analisis deskriptif. Dalam mengambil responden, penelitian ini menggunakan teknik non probability sampling di mana teknik ini tidak memberi peluang yang sama kepada anggota populasi untuk dipilih menjadi anggota sampel. Jenis sampling yang dipilih adalah incidental sampling. Dalam penelitian ini, ukuran populasi tidak diketahui sehingga untuk menentukan ukuran sampelnya digunakan rumus model iterasi (Sudradjat, 2002) sehingga didapatkan hasil responden berjumlah 62 orang. Pengumpulan data dilakukan dengan menggunakan kuesioner yang berisi pertanyaan yang terdiri dari variabelvariabel yang berkaitan dengan penelitian. Analisis menggunakan metode analisis deskriptif, Importance Performance Analysis (IPA) serta analisis Customer Satisfaction Index (CSI). Analisis deskriptif akan digunakan untuk menggambarkan karakteristik responden yang membeli dan pernah mengonsumsi minuman kopi Java Preanger. Tujuan analisis ini adalah untuk membuat deskripsi secara sistematis, faktual akan fakta-fakta, sifat-sifat, serta hubungan antara fenomena yang diselidiki.

IPA digunakan untuk menganalisis tingkat kepuasan konsumen dengan cara membandingkan kesesuaian antara tingkat kepentingan dengan tingkat kinerja suatu atribut yang dimiliki oleh produk dengan merek tertentu. Kelebihan metode IPA dibandingkan metode lain yaitu prosedur yang digunakan cukup sederhana, pengambil kebijakan dapat dengan mudah menentukan prioritas kegiatan yang harus dilakukan dengan sumberdaya yang terbatas, serta metode ini cukup fleksibel untuk diterapkan pada berbagai bidang (Tjiptono,2005).

Langkah-langkah dalam metode IPA adalah: 1) Menghitung tingkat kesesuaian dengan membandingkan skor kinerja dengan skor kepentingan; 2) Menghitung rataan untuk setiap atribut kualitas minuman kopi; 3) Menghitung rataan seluruh atribut tingkat kepentingan dan tingkat kinerja yang akan menjadi batas pada diagram kartesius; 4)
Melakukan pemetaan ke dalam diagram kartesius untuk melihat posisi masing-masing atribut kualitas produk.

CSI digunakan untuk melihat tingkat kepuasan konsumen terhadap atribut kualitas produk secara menyeluruh. Pengukuran terhadap indeks kepuasan pelanggan diperlukan karena hasil dari pengukuran tersebut dapat digunakan sebagai acuan untuk menentukan sasaran-sasaran di tahun-tahun mendatang. Selain itu indeks juga diperlukan karena proses pengukuran kepuasan pelanggan bersifat kontinyu.

Cara menghitung indeks kepuasan pelanggan adalah: 1) Menghitung weighted factor yaitu mengubah nilai rata-rata tingkat kepentingan menjadi angka persen, sehingga didapatkan total weighting factor $100 \%$; 2) Menghitung weighting score, yaitu nilai perkalian antara nilai rata-rata tingkat kinerja dengan weighting factor; 3) Menghitung weighted total, yaitu menjumlahkan weighted score dari semua atribut; 4) Menghitung satisfaction index, yaitu weighted total dibagi skala maksimal yang digunakan (dalam penelitian ini skala maksimum yang digunakan adalah 5) kemudian dikali 100\%. Adapun indikator untuk mengukur kriteria kepuasan konsumen adalah sebagai berikut:

Tabel 1. Kriteria Indeks Kepuasan Konsumen

\begin{tabular}{cc}
\hline Nilai CSI & Kriteria CSI \\
\hline $0,81-1,00$ & Sangat Puas \\
$0,66-0,80$ & Puas \\
$0,51-0,65$ & Cukup Puas \\
$0,35-0,50$ & Kurang Puas \\
$0,00-0,34$ & Tidak Puas \\
\hline
\end{tabular}

Sumber: Sukardi dan Cholidis (2006)

\section{HASIL DAN PEMBAHASAN \\ Gambaran Umum Perusahaan}

Java Preanger Coffee House adalah salah satu kedai kopi di kota Bandung yang baru berdiri pada tahun 2013. Pendirian Java Preanger Coffee House ini juga diresmikan bersama dengan Clearing House Kopi Jawa Barat pada tanggal 6 Juli 2013, yang diresmikan dan dikukuhkan oleh Gubernur Jawa Barat. Clearing House Kopi Jabar ini sendiri berfungsi sebagai sarana mewadahi para stakeholders kopi se-Jawa Barat untuk dapat berkumpul dan bertukar informasi di sebuah forum yang bertujuan untuk mengangkat kopi Jawa Barat yaitu kopi Java Preanger di tataran Provinsi Jawa Barat khususnya dan pada tingkat nasional serta internasional. 
Java Preanger Coffee House menyatakan bahwa mereka adalah respresentasi jati diri kopi arabika single origin produk Jawa Barat dalam rangka membangun karakter dan cita rasa kopi melalui kegiatan promosi, perdagangan, wisata, edukasi, dan seni kuliner kopi untuk produsen dan konsumen kopi Java Preanger. Kedai kopi ini khusus menyediakan minuman kopi yang biji kopinya hanya diambil dari seluruh sentra produksi kopi Java Preanger berbasis indikasi geografis (IG), yang meliputi Gunung Cikuray, Gunung Papandayan, Gunung Malabar, Gunung Wayang, Gunung Tilu, Gunung Patuha, Gunung Halu, Gunung Tangkuban Perahu dan Gunung Manglayang.

\section{Karakteristik Responden}

Karakteristik konsumen minuman kopi di Java Preanger Coffee House yaitu berjenis kelamin laki-laki dengan rentang usia 25-30 tahun dan memiliki pekerjaan di bidang swasta. Tempat tinggal responden berada di kota Bandung dan memiliki pendapatan dengan di atas Rp5.000.000 per bulannya serta berpendidikan akhir sebagai sarjana. Data karakteristik responden secara umum dapat dilihat pada Tabel 2.

\section{Hasil IPA}

\section{Tingkat Kesesuaian}

Tingkat kesesuaian adalah hasil perbandingan skor persepsi dengan skor yang diharapkan. Tingkat kesesuaian inilah yang nantinya akan menentukan urutan prioritas atribut kualitas produk minuman kopi, mulai dari urutan yang sangat sesuai hingga tidak sesuai. Tabel 3 memperlihatkan tingkat kesesuaian yang kemudian akan menentukan urutan prioritas pengoptimuman faktor-faktor yang nantinya akan mempengaruhi kepuasan pelanggan.

Pada Tabel 3 dapat dilihat bahwa atribut kualitas yang memiliki tingkat kesesuaian paling tinggi adalah variasi rasa, yang diikuti oleh atribut ukuran volume atau isi dengan masing-masing tingkat kesesuaian 106\% dan 104,85\%. Setelah itu, untuk atribut lainnya yang memiliki nilai berkisar antara 90\% hingga 100\% adalah atribut manfaat, tampilan fisik, kenyamanan tempat, informasi menu, serta pelayanan. Lalu, atribut yang memiliki kisaran nilai antara $80 \%$ hingga 90\% meliputi atribut rasa, harga, aroma dan kualitas bahan baku. Atribut terakhir yang memiliki nilai terendah adalah atribut cara penyajian dengan tingkat kesesuaian sebesar $76 \%$.

\section{Diagram Kartesius IPA}

Dalam metode IPA, data dianalisis menggunakan diagram kartesius yang bertujuan untuk mengetahui bagaimana prioritas yang ditempatkan oleh masing-masing atribut kualitas produk. Analisis ini juga dapat digunakan untuk mengidentifikasi langkahlangkah perbaikan dengan melihat prioritas dari masing-masing atribut kualitas produk. Langkah dalam analisi IPA adalah dengan menjabarkan variabel ke dalam diagram kartesius berdasarkan penilaian tingkat kinerja atribut kualitas produk minuman kopi dan penilaian tingkat kepentingannya. Sumbu X di sini merupakan tingkat kinerja atribut kualitas produk minuman kopi dan sumbu Y adalah tingkat kepentingannya.

Tabel 2. Karakteristik Responden

\begin{tabular}{|c|c|c|}
\hline Deskripsi & $\mathrm{n}$ & Presentase \\
\hline \multicolumn{3}{|l|}{ Usia } \\
\hline 19-24 tahun & 15 & $24,2 \%$ \\
\hline 25-30 tahun & 21 & $33,8 \%$ \\
\hline 31-36 tahun & 3 & $4,8 \%$ \\
\hline $37-42$ tahun & 7 & $11,3 \%$ \\
\hline 43-48 tahun & 7 & $11,3 \%$ \\
\hline 49-54 tahun & 6 & $9,8 \%$ \\
\hline 55-60 tahun & 3 & $4,8 \%$ \\
\hline \multicolumn{3}{|l|}{ Jenis Kelamin } \\
\hline Laki-laki & 40 & $64,5 \%$ \\
\hline Perempuan & 22 & $35,5 \%$ \\
\hline \multicolumn{3}{|l|}{ Pekerjaan } \\
\hline PNS & 9 & $9 \%$ \\
\hline Swasta & 22 & $35,3 \%$ \\
\hline Wiraswasta & 13 & $21 \%$ \\
\hline Pelajar & 15 & $24,2 \%$ \\
\hline IRT & 2 & $3,2 \%$ \\
\hline BUMN & 1 & $1,6 \%$ \\
\hline \multicolumn{3}{|l|}{ Tempat Tinggal } \\
\hline Bandung & 48 & $77,4 \%$ \\
\hline Jakarta & 7 & $11,3 \%$ \\
\hline Bogor & 2 & $3,2 \%$ \\
\hline Bengkulu & 1 & $1,6 \%$ \\
\hline Cimahi & 3 & $4,8 \%$ \\
\hline Jatinangor & 1 & $1,6 \%$ \\
\hline \multicolumn{3}{|l|}{ Pendapatan } \\
\hline$<\operatorname{Rp} 1.000 .000$ & 4 & $6,5 \%$ \\
\hline Rp 1.000.001-3.000.000 & 15 & $24,2 \%$ \\
\hline Rp 3.000.001-5.000.000 & 11 & $17,7 \%$ \\
\hline$>\mathrm{Rp} 5.000 .001$ & 32 & $51,6 \%$ \\
\hline \multicolumn{3}{|l|}{ Pendidikan Terakhir } \\
\hline SMA & 12 & $19,4 \%$ \\
\hline Diploma & 8 & $12,9 \%$ \\
\hline Sarjana & 37 & $59,7 \%$ \\
\hline Magister & 5 & $8,1 \%$ \\
\hline
\end{tabular}

Sumber: Data diolah (2015) 
Tabel 3. Tingkat Kesesuaian dari Kepentingan dan Kinerja Minuman Kopi Java Preanger

\begin{tabular}{lllllll}
\hline No & Atribut Kualitas Produk & $\begin{array}{l}\text { Tingkat } \\
\text { Kinerja } \\
(\mathrm{Xi})\end{array}$ & $\begin{array}{l}\text { Tingkat } \\
\text { Kepentingan } \\
(\text { Yi })\end{array}$ & $\begin{array}{l}\text { Tingkat } \\
\text { Kesesuaian } \\
(\text { Tki) }\end{array}$ & $\begin{array}{l}\text { Rata-rata } \\
\text { Tingkat } \\
\text { Kinerja } \\
(\mathrm{Xi})\end{array}$ & $\begin{array}{l}\text { Rata-rata } \\
\text { Tingkat } \\
\text { Kepentingan } \\
(\text { Yi) }\end{array}$ \\
\hline 1 & Rasa & 250 & 285 & $87,7 \%$ & 4,03 & 4,59 \\
2 & Harga & 221 & 255 & $86,67 \%$ & 3,56 & 4,11 \\
3 & Aroma & 227 & 265 & $85,6 \%$ & 3,66 & 4,27 \\
4 & Variasi Rasa & 228 & 215 & $106 \%$ & 3,67 & 3,45 \\
5 & Manfaat & 223 & 232 & $96,12 \%$ & 3,59 & 3,74 \\
6 & Tampilan Fisik & 210 & 214 & $98,13 \%$ & 3,38 & 3,45 \\
7 & Cara Penyajian & 227 & 299 & $76 \%$ & 3,66 & 4,82 \\
8 & Kualitas Bahan Baku & 242 & 273 & $88,65 \%$ & 3,90 & 4,40 \\
9 & Kenyamanan Tempat & 245 & 262 & $93,5 \%$ & 3,95 & 4,22 \\
10 & Ukuran/Volume Isi & 216 & 206 & $104,85 \%$ & 3,48 & 3,32 \\
11 & Informasi Menu & 208 & 231 & $90 \%$ & 3,35 & 3,72 \\
12 & Pelayanan & 230 & 255 & $90,2 \%$ & 3,70 & 4,11 \\
\hline Rata-rata & & & $\mathbf{9 1 , 9 5 \%}$ & $\mathbf{3 , 6 6}$ & $\mathbf{4 , 0 2}$ \\
\hline
\end{tabular}

Sumber: Data diolah (2015)

\section{Kuadran I (Prioritas Utama)}

Pertama, harga. Menurut Kotler (2003), pada lebih dari 70 persen bisnis yang dipelajari, harga mencetak nilai yang pertama dan kedua sebagai fitur dengan apa para pelanggan paling tidak bisa dipuaskan. Harga di sini memiliki arti bahwa apakah harga yang dibayarkan konsumen sesuai dengan kualitas yang diterima. Harga minuman kopi yang ditawarkan oleh pihak Java Preanger Coffee House dari Rp30.000 hingga Rp100.000 untuk kopi luwak. Dilihat dari data yang telah dikumpulkan, harga memiliki tingkat kepentingan sebesar 255 yang berarti konsumen menilai harga sebagai salah satu indikator yang penting namun kinerja yang diberikan atribut harga belum sesuai.

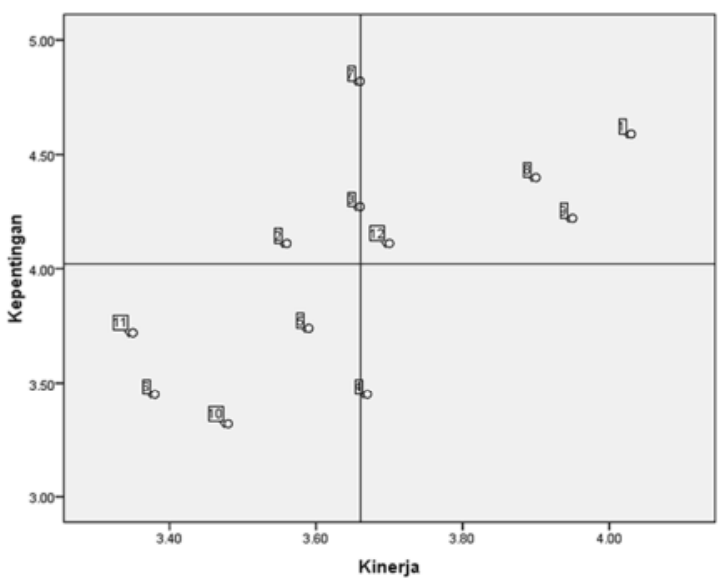

Gambar 2. Diagram Kartesius IPA

Kedua, aroma. Aroma merupakan salah satu faktor yang dipertimbangkan oleh konsumen ketika mereka mengonsumsi kopi. Namun, atribut aroma belum memberikan kinerja yang diharapkan oleh responden di mana tingkat kepentingan aroma tersebut dinyatakan sangat penting bagi responden, yaitu memiliki nilai sebesar 265. Hal ini dapat disebabkan oleh kopi Java Preanger Coffee House menggunakan jenis kopi arabika yang aromanya tidak sekuat kopi robusta. Salah satu cara menanggulanginya adalah dengan memberikan edukasi kepada konsumen mengenai aroma kopi arabika, baik melalui informasi tambahan pada buku menu, pada dekorasi kedai kopi, maupun penjelasan dari pramusaji.

Ketiga, cara penyajian. Cara penyajian di sini memiliki arti bagaimana pramusaji bersikap dan melayani para pelanggan, dari mulai kesopanan, kebersihan, keramahan hingga kerapihan dalam menyajikan hidangan. Atribut cara pelayanan belum memberikan kinerja sesuai yang diharapkan responden, di mana atribut ini memiliki nilai 299 yang berarti dapat dikategorikan sangat penting. Hal ini dapat dijadikan referensi bagi pihak Java Preanger Coffee House untuk lebih menekankan cara penyajian yang lebih baik lagi bagi para pramusajinya.

\section{Kuadran II (Pertahankan Prestasi) \\ Pertama, rasa. Rasa minuman kopi} sudah dianggap baik oleh konsumen dan perlu dipertahankan oleh pihak kedai kopi, agar dapat meningkatkan penjualan dan dapat meningkatkan kepuasan konsumennya. Salah satu konsumen menyatakan bahwa rasa kopi yang ditawarkan kedai kopi ini khas dan berbeda dengan kedai kopi lain yang pernah ia kunjungi. 
Kedua, kualitas bahan baku. Kualitas bahan baku tentunya sangat penting untuk mendapatkan hasil akhir rasa kopi yang nikmat. Atribut ini dirasa sudah dapat memuaskan konsumen Java Preanger Coffee House dan pihak pengelola perlu mempertahankan kualitas bahan baku yang mereka gunakan dalam menyajikan kopi. Kualitas bahan baku juga telah menjadi standar yang tidak boleh diubah secara bebas bagi pihak kedai kopi karena sangat penting untuk terus menjaga kualitas yang baik.

Ketiga, kenyamanan tempat. Atribut kenyamanan tempat dianggap sudah dapat memuaskan konsumen, di mana atribut ini memiliki nilai 262 yang berarti sangat penting dan kinerjanya pun memenuhi harapan konsumen. Beberapa responden mengatakan bahwa Java Preanger Coffee House termasuk kedai kopi yang memiliki suasana yang tenang atau tidak bising sehingga responden nyaman untuk berlama-lama di kedai kopi ini. Fasilitas yang diberikan oleh pihak Java Preanger Coffee House di kedai kopinya berupa tempat parkir yang luas, free hot spot, toilet, mushola serta ruang khusus untuk mengadakan rapat.

Keempat, pelayanan. Atribut ini dapat dikatakan telah memenuhi kinerja yang diharapkan oleh konsumen. Meskipun jumlah pramusaji yang terdapat di Java Preanger Coffee House tidak begitu banyak, namun kesigapan pramusaji dalam melayani konsumen termasuk cukup cepat dan sigap.

\section{Kuadran III (Prioritas Rendah)}

Pertama, manfaat. Keberadaan atribut manfaat di sini memiliki arti bagaimana manfaat yang responden rasakan setelah mengonsumsi kopi Java Preanger Coffee House, seperti kesegaran yang dirasakan. Atribut ini dirasa kurang penting dan tidak begitu dihiraukan oleh responden.

Kedua, tampilan fisik. Atribut tampilan fisik pada konteks ini meliputi bagaimana penyajian kopi terlihat menarik, rapi, dan juga bersih. Selain itu juga penambahan gambar pada permukaan minuman kopi atau biasa disebut latte art dapat menjadi penilaian tambahan untuk atribut tampilan fisik. Responden pun tidak begitu mempertimbangkan atribut ini karena mayoritas responden menyatakan mereka lebih mengutamakan dan mementingkan atribut lain seperti rasa.

Ketiga, ukuran volume atau isi. Atribut ukuran volume minuman kopi tidak begitu diperhitungkan oleh responden, karena mereka menyatakan bahwa ukuran volume minuman yang biasa kedai kopi sajikan memang sudah standar ukurannya. Responden pun tidak menuntut bahwa ukuran volume minuman harus diperbesar karena berdasarkan pengalaman yang responden alami di kedai kopi lain pun sama halnya dengan ukuran volume minuman kopi di Java Preanger.

Keempat, informasi menu. Atribut informasi menu dinyatakan kurang penting dan kinerjanya pun dirasa biasa saja oleh responden. Hal ini dapat disebabkan karena dengan banyaknya varian minuman kopi yang terdapat dalam daftar menu, responden pun tetap akan bertanya lebih dahulu kepada pramusaji mengenai minuman kopi yang mereka inginkan walaupun sudah terdapat informasi khusus mengenai masing-masing varian menu minuman kopi. Responden menganggap bahwa informasi menu minuman kopi yang dicantumkan di daftar menu kurang mudah untuk dimengerti sehingga mereka tetap harus bertanya lebih lanjut kepada pramusaji.

\section{Kuadran IV (Berlebihan)}

Pertama, variasi rasa. Java Preanger

Coffee House menyediakan lebih dari 15 variasi menu minuman kopi yang responden nyatakan bahwa hal ini ternyata kurang penting. Hal ini disebabkan oleh biasanya konsumen memilih menu minuman kopi yang standar, seperti black coffee, kopi luwak dan cappucino. Namun dengan adanya variasi menu minuman kopi yang cukup banyak, responden akhirnya memiliki pilihan yang lebih banyak untuk minuman kopinya.

\section{Hasil CSI}

Hasil dari pengukuran Customer Satisfaction Index dapat dilihat pada Tabel 4 di bawah ini. Tabel 4 menunjukkan nilai CSI sebesar $73,6 \%$ di mana nilai tersebut berada di antara nilai 0,66-0,80 yang termasuk ke dalam kategori puas. Pelanggan sudah mencapai tingkatan puas terhadap keseluruhan atribut kualitas produk minuman kopi yang diberikan oleh pihak Java Preanger Coffee House. Namun, akan lebih baik jika pihak Java Preanger Coffee House dapat terus meningkatkan kinerjanya agar konsumen dapat merasa sangat puas terhadap kinerja yang diberikan.

Apabila dihubungkan dengan hasil analisis IPA, nilai CSI yang masih berada di bawah 0,80 
dapat disebabkan oleh atribut kepuasan yang berada di kuadran I yang menjadi prioritas utama dan harus ditingkatkan kinerjanya dan kuadran III yang menjadi prioritas selanjutnya untuk ditingkatkan kinerjanya.

\section{KESIMPULAN}

Berdasarkan hasil penelitian, dapat diambil kesimpulan sebagai berikut: (1) Karakteristik konsumen produk minuman kopi di Java Preanger Coffee House didominasi oleh responden dengan jenis kelamin laki-laki yang berada pada kisaran usia 25-30 tahun dan memiliki pekerjaan di bidang swasta. Tempat tinggal responden berada di kota

Tabel 4. Data Hasil Perhitungan CSI

\begin{tabular}{|c|c|c|c|c|}
\hline Atribut & $\begin{array}{l}\text { Rata-an } \\
\text { Skor } \\
\text { Kepenting } \\
\text { an }\end{array}$ & $\begin{array}{l}\text { Weigh- } \\
\text { ted } \\
\text { Factor }\end{array}$ & $\begin{array}{l}\text { Rataan } \\
\text { Skor } \\
\text { Kinerja }\end{array}$ & $\begin{array}{l}\text { Neig- } \\
\text { iting } \\
\text { icore }\end{array}$ \\
\hline Rasa & 4,59 & 0,095 & 4,03 & ), 38 \\
\hline Harga & 4,11 & 0,085 & 3,56 & ), 30 \\
\hline Aroma & 4,27 & 0,088 & 3,66 & ),32 \\
\hline Variasi Rasa & 3,45 & 0,071 & 3,67 & ), 26 \\
\hline Manfaat & 3,74 & 0,077 & 3,59 & ),28 \\
\hline $\begin{array}{l}\text { Tampilan } \\
\text { Fisik }\end{array}$ & 3,45 & 0,071 & 3,38 & ),24 \\
\hline $\begin{array}{l}\text { Cara } \\
\text { Penyajian }\end{array}$ & 4,82 & 0,100 & 3,66 & ),37 \\
\hline $\begin{array}{l}\text { Kualitas } \\
\text { Bahan Baku }\end{array}$ & 4,40 & 0,091 & 3,90 & ),36 \\
\hline $\begin{array}{l}\text { Kenyaman-an } \\
\text { Tempat }\end{array}$ & 4,22 & 0,087 & 3,95 & ),35 \\
\hline Volume Isi & 3,32 & 0,068 & 3,48 & ),24 \\
\hline $\begin{array}{l}\text { Informasi } \\
\text { Menu }\end{array}$ & 3,72 & 0,077 & 3,35 & ),26 \\
\hline Pelayanan & 4,11 & 0,085 & 3,70 & ),32 \\
\hline Jumlah Total & 48,2 & 1,00 & 43,93 & 3,68 \\
\hline $\begin{array}{l}\text { Customer Satis } \\
\text { (Weighting To }\end{array}$ & $\begin{array}{l}\text { faction Inc } \\
\text { tal/5) } \times 10\end{array}$ & & & 73.6 \\
\hline
\end{tabular}

Sumber: Data diolah (2015)

Bandung dan memiliki pendapatan di atas Rp 5.000.000 per bulannya serta memiliki pendidikan terakhir sebagai sarjana; (2) Berdasarkan hasil perhitungan Importance Performance Analysis didapatkan atribut yang memiliki tingkat kepentingan yang tinggi namun kinerjanya perlu ditingkatkan adalah atribut harga, aroma dan cara penyajian. Lalu, atribut yang memiliiki kepentingan yang tinggi dan kinerja yang telah memuaskan meliputi atribut rasa, kualitas, bahan baku, kenyamanan tempat serta pelayanan. Atribut yang memiliki kinerja yang biasa saja serta tingkat kepentingannya bagi konsumen termasuk rendah adalah atribut manfaat, tampilan fisik, ukuran volume atau isi dan informasi menu. Sementara itu, hanya terdapat satu atribut yang konsumen anggap kurang penting pengaruhnya namun kinerjanya berlebihan, atribut tersebut adalah variasi rasa; dan (3) Berdasarkan hasil perhitungan indeks kepuasan konsumen yang memiliki niai 73,6\%, dapat dikatakan bahwa para konsumen minuman kopi Java Preanger Coffee House merasa puas atas kinerja atribut kualitas produk minuman kopi Java Preanger secara keseluruhan.

Java Preanger Coffee House harus lebih memfokuskan kinerjanya yang dianggap penting oleh konsumen yaitu pada atribut harga, aroma, serta cara penyajian. Hal ini dapat dilakukan dengan cara menggunakan strategi yang lebih baik pada atribut harga, seperti meningkatkan kualitas produknya sehingga sesuai dengan harga yang ditawarkan. Atribut cara pelayanan dapat diperbaiki dan ditingkatkan kinerjanya dengan cara memberikan pelatihan dan pengetahuan yang lebih intensif kepada pramusaji mengenai pentingnya pelayanan sehingga dapat meningkatkan kualitas pelayanannya. Atribut aroma dapat ditingkatkan dengan menggunakan teknik pengolahan yang lebih baik lagi agar aroma kopi lebih terasa wanginya. Di samping itu, pihak pengelola harus tetap dapat mempertahankan kinerjanya pada atribut rasa, kualitas bahan baku, kenyamanan tempat dan pelayanan yang sudah membuat konsumen puas. Hal ini perlu dilakukan untuk tetap mempertahankan dan meningkatkan konsumen serta bertahan dari para pesaing usaha kedai kopi sejenis yang semakin menjamur.

Mempertahankan serta meningkatkan prestasi pelaksanaan atribut yang penting di mata konsumen agar tingkat kepuasan keseluruhan atribut minuman kopi dapat memuaskan bagi para konsumen dan juga melakukan perbaikan secara optimal terhadap atribut minuman kopi yang kinerjanya dirasa kurang di mata konsumen.

Penelitian selanjutnya diharapkan untuk meneliti variabel lain selain atribut produk yang memiliki pengaruh terhadap kepuasan konsumen, contohnya variabel pemasaran lainnya yang meliputi promosi and distribusi (place).

\section{DAFTAR PUSTAKA}

Anggita, Priscilla. 2014. Analisis Kepuasan Konsumen Terhadap Kualitas Minuman Kopi dengan Metode Importance Performance Analysis (IPA) dan Customer Satisfaction Index (CSI) di Coffee Story 
Malang. Malang: Teknologi Industri Pangan Fakultas Teknologi Pangan Universitas Brawijaya.

Coffee Consumption in East and Southeast Asia: 1990 - 2012. 2014. London, United Kingdom: Int'l Coffee Organization.

Dinas Perkebunan Provinsi Jawa Barat. 2014. Perlindungan Indikasi Geografis (IG) Kopi Arabika Java Preanger (KAJP). http://disbun.jabarprov.go.id/. Diakses pada 29 November 2014.

Fornell C, Michael D. Johnson, Eugene W. Anderson, Jaesung Cha, and Barbara Everitt Bryant. 1996. The American Customer Satisfaction Index: Nature, Purpose, and Finding Journal of Marketing Vol. 60 (October 1996), 7-18

Irawan. 2008. Sepuluh Prinsip Kepuasan Pelanggan. Jakarta: Penerbit Elex Media Komputindo Kelompok Gramedia.

Kotler, Philip. 2000. Manajemen Pemasaran, Edisi Milenium 1. Prenhallindo: Jakarta.

Kotler et al. 2008. Manajemen Pemasaran, Edisi 12. Penerbit PT. Macanan Jaya Cemerlang. Jakarta.

Lestari, dkk. 2009. Konsumsi Kopi Masyarakat Perkotaan dan Faktor-Faktor yang Berpengaruh: Kasus di Kabupaten Jember. Pelita Perkebunan, Vol 25 (3), Hal 216-235.

Matanda, M. , Movondo, F., and Schorder, B. Customer Satisfaction: An Evaluation Of Horticutural Produce Purchasers. Proceedings of ANZMAC99 Marketing In The Third Millenium. 28 November - 1 Desember 1999.a

Putu, Gusti Ayu. 2014. Pengaruh Kualitas Pelayanan terhadap Kepuasan dan Loyalitas Nasabah PT BPR Hoki Di Kabupaten Tabanan. Denpasar: Program Magister Program Studi Manajemen Program Pascasarjana Univ. Udayana. Qomariyah, dkk. 2014. Analisis Sikap Konsumen dan Kinerja Atribut Minuman
Kopi Sido Luhur (Studi Kasus di UKM Kopi Bubuk Sido Luhur, Kota Malang). Jurnal Industria, Vol 3, No 1, Hal 53 - 61.

Rachmad. 2014. Pengaruh Kualitas Layanan, Produk, serta Persepsi Konsumen terhadap Kepuasan dan Niat Berperilaku Konsumen. Bogor: Program Pascasarjana Manajemen Bisnis Institut Pertanian Bogor.

Rangkuti. 2009. Strategi Promosi yang Kreatif dan Analisis Kasus Integrated Marketing Communication. Jakarta: Gramedia Pustaka Utama.

Sudradjat. 2002. Metode Penarikan Sampel dan Penyusunan Skala. Jatinangor: Fakultas Pertanian Universitas Padjadjaran.

Sugiyono. 2011. Metode Penelitian Kuantitatif, Kualitatif dan R\&D. Alfabeta: Bandung.

Sumarwan, Ujang. 2003. Perilaku Konsumen. Jakarta: Penerbit Ghalia Indonesia.

Shelvi, Nike. 2014. Pengaruh Atribut Produk Terhadap Keputusan Pembelian di UKM Brosem Batu. Malang: Jurusan Teknologi Industri Pertanian Universitas Brawijaya.

Sukardi dan C. Chandrawatisma. 2006. Analisis Tingkat Kepuasan terhadap Produk Corned Pronas Produksi PT CIP, Denpasar-Bali. Jurnal Teknologi Industri Pertanian 18(2):106-107.

Tjiptono, F. dan Gregorius, C. 2005. Service, Quality \& Satisfaction Edisi Ketiga. Penerbit Andi. Yogyakarta.

Weni. 2011. Analisis Kinerja Produk UKM Batik Banyumas dengan Menggunakan Metode Importance Performance Analysis (IPA) dan Potential Gain of Customer Value's (PGCV) Index (Product Performance Analysis of Batik Banyumas Smes Using Importance Performance Analysis (IPA) and Potential Gain of Customer Value's (PGCV) Index). Jurnal Bisnis dan Ekonomi (JBE), Vol 18, No 2, Hal 104-113. 